\title{
Insights on the Stabilization of Nickel-Rich Cathode Surfaces: Evidence of Inherent Instabilities in the Presence of Conformal Coatings
}

\author{
Jason R. Croy, Daniel C. O’Hanlon, Soroosh Sharifi-Asl, Michael Murphy, Anil Mane, \\ Chang- Wook Lee, Stephen E. Trask, Reza Shahbazian-Yassar, and Mahalingam \\ Balasubramanian
}

\section{Supplemental Information}

Pouch Cell Assembly - Pouch cell assembly was conducted in a climate-controlled dry-room with dew point less than $-42^{\circ} \mathrm{C}(<100 \mathrm{ppm}$ moisture). These custom single-interface stack-type cells adhere to processes and equipment used in previous work (REF). Each pouch cell consists of a single-sided positive electrode punched with a 9/16" notched edge punch (to allow bare aluminum foil to extend $\sim 10 \mathrm{~mm}$ for welding purposes to aluminum metal pouch tabbing), layer of Celgard 2325 (PP/PE/PP) separator, and negative electrode (lithium metal) ultrasonically welded to nickel metal pouch tabbing. Pouch laminate was then positioned around the cell with both sides of the cell having $1 / 4$ " hole punches located directly above the area of interest. The $1 / 4$ " opening in the pouch material serves to minimize signal interference during hard X-ray spectroscopy probing through the lithium metal and separator, since the coating on the positive electrode is the item of interest for this study. Kapton tape was used on both the inside and outside of the $1 / 4$ " hole in the pouch laminate to provide added protection from the outside atmosphere. The cell components were then manually aligned and sealed using a tab area heat sealer (profiled bars) to prevent leaks at the tab locations and a side area heat sealer (flat bars) while leaving one side open for adding the electrolyte. Each cell was then filled with $0.5 \mathrm{~mL}$ of $1.2 \mathrm{M} \mathrm{LiPF} 6$ in EC:EMC (3:7 by weight) and sealed under an 18 second vacuum. A follow up side area seal was then performed on the vacuum sealed side to ensure proper sealing. The cells were then fixed to rigid, nonconductive boards to undergo electrochemical testing.

(REF) S. E. Trask, Y. Li, J. J. Kubal, M. Bettge, B. J. Polzin, Y. Zhu, A. N. Jansen, and D. P. Abraham. From coin cells to $400 \mathrm{mAh}$ pouch cells: Enhancing performance of high-capacity lithium-ion cells via modifications in electrode constitution and fabrication. J. Power Sources, 259, 233 (2014).

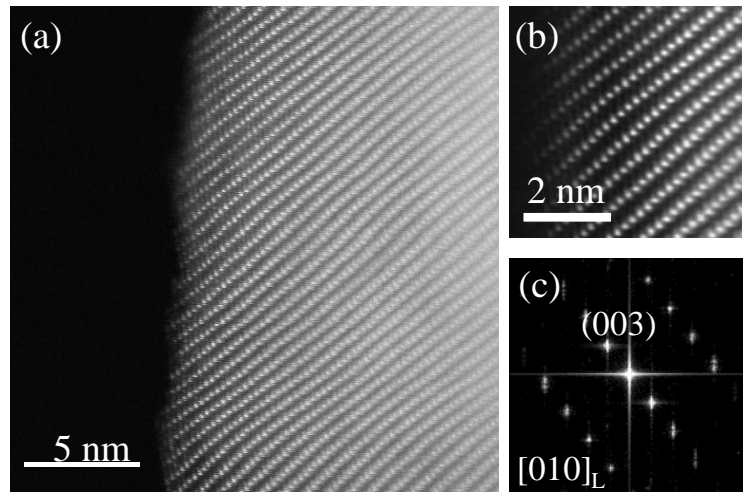

Figure S1 - (a) Atomic resolution images from the surfaces of the Ni-doped $600^{\circ} \mathrm{C}$ particles. The atomic resolution image in panel (a) is filtered and shown in panel (b) for a clearer demonstration. (c) Corresponding fast Fourier transform (FFT) of image (a). 

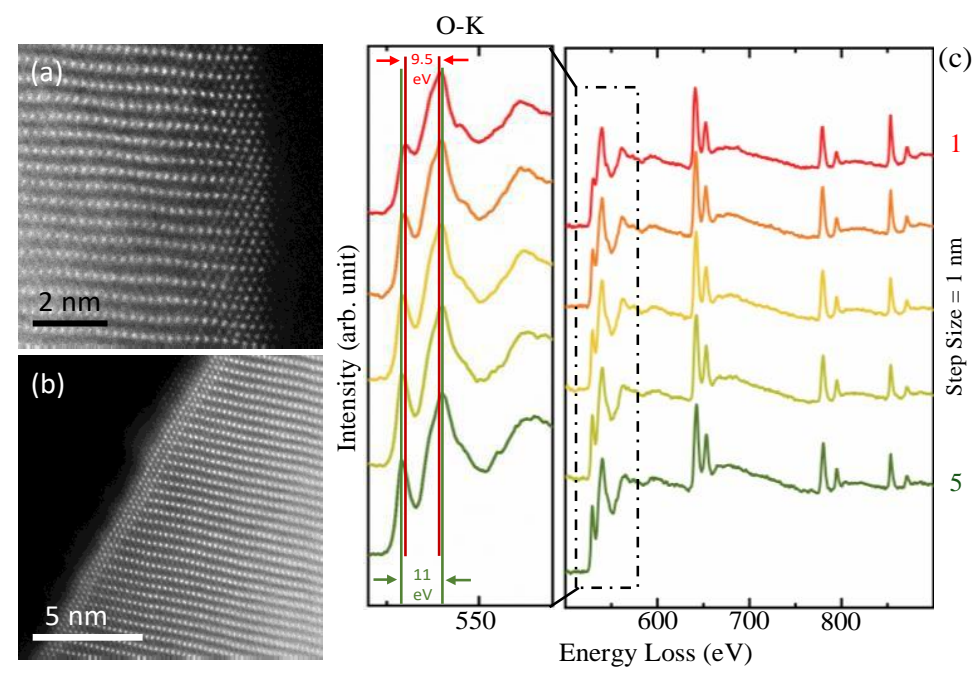

Figure S2a - High resolution images of surface reconstruction layers found on pristine NMC622 (a) and NMC-111 (b) cathode particles. The NMC-622 is a commercially available material (Toda) and the NMC-111 was prepared in-house (Jian Zhu and Guoying Chen, LBNL). (c) EELS spectra taken at a $1 \mathrm{~nm}$ step size to show the changes in the $\mathrm{O}-\mathrm{K}$ edge in the reconstructed surface region of the NMC-111 particle in (b).
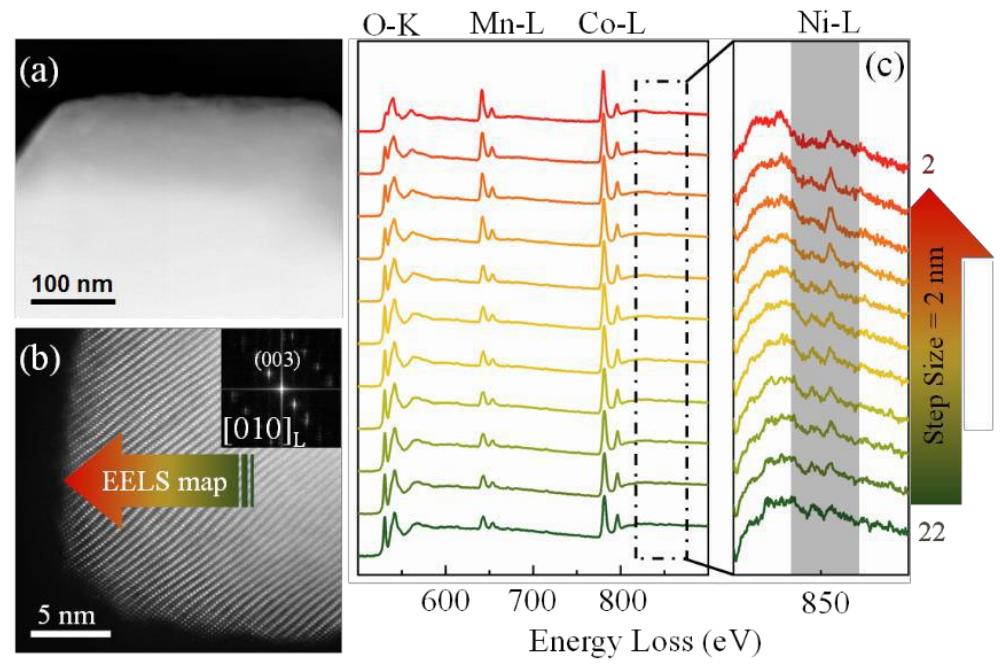

Figure S2b -Changes to O-edge can be observed at the surface of the $\mathrm{Ni}-600^{\circ} \mathrm{C}$ sample, if the probe size is decreased ( $2 \mathrm{~nm}$ here). This is due to the native reconstruction found on virtually all NMC oxides as illustrated in Figure S2a. 


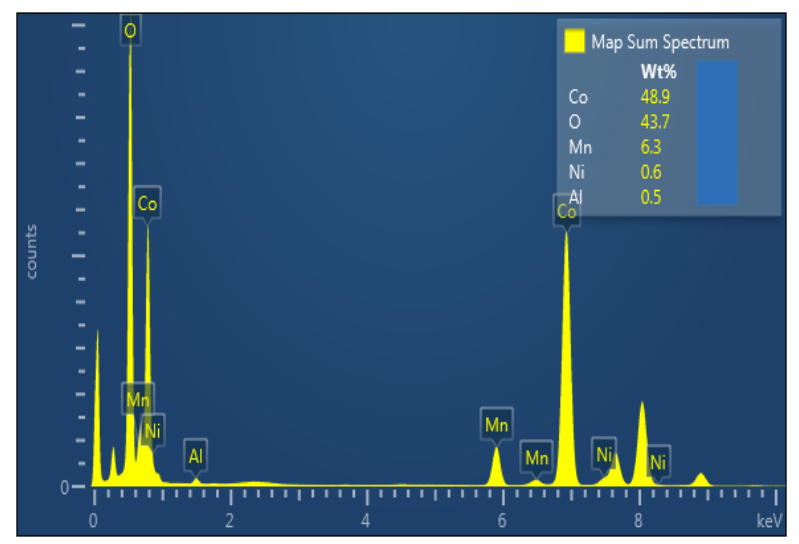

Figure S3 - EDS map summary data from $\mathrm{Al}_{2} \mathrm{O}_{3}$-coated electrodes presented in Figure 4 of the main text.

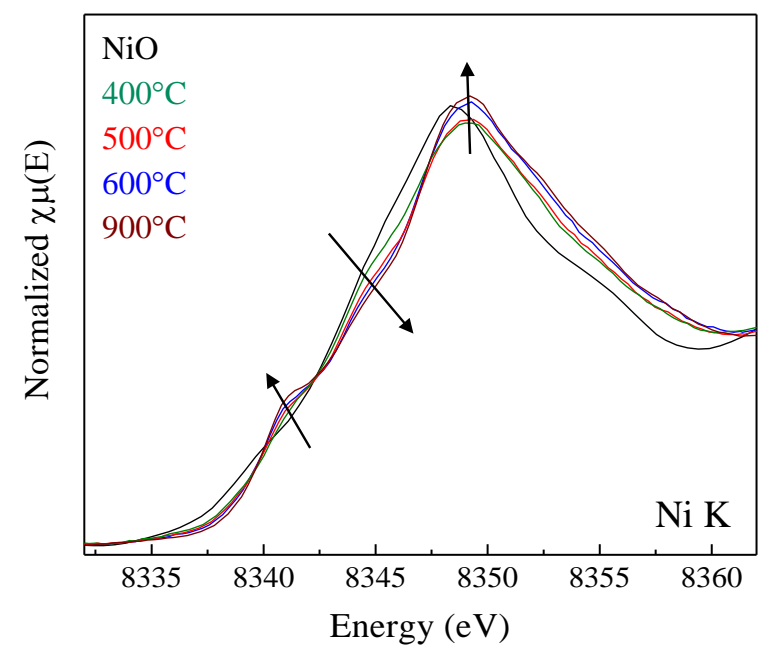

Figure S4 - Evolution of the Ni K-edge XANES as a function of annealing from 400 to $900^{\circ} \mathrm{C}$ of the Ni-doped LCMO. 

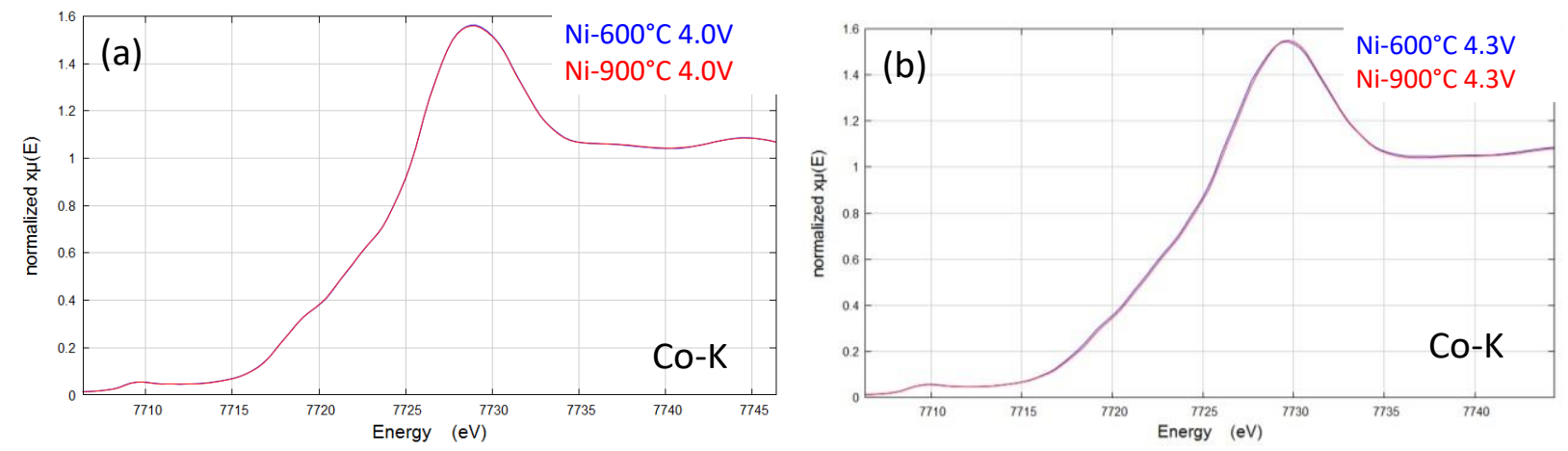

Figure S5 - Co K-edge XANES data of the Ni-600/900 ${ }^{\circ} \mathrm{C}$ samples charged to (a) 4.0 and (b) 4.3 V.
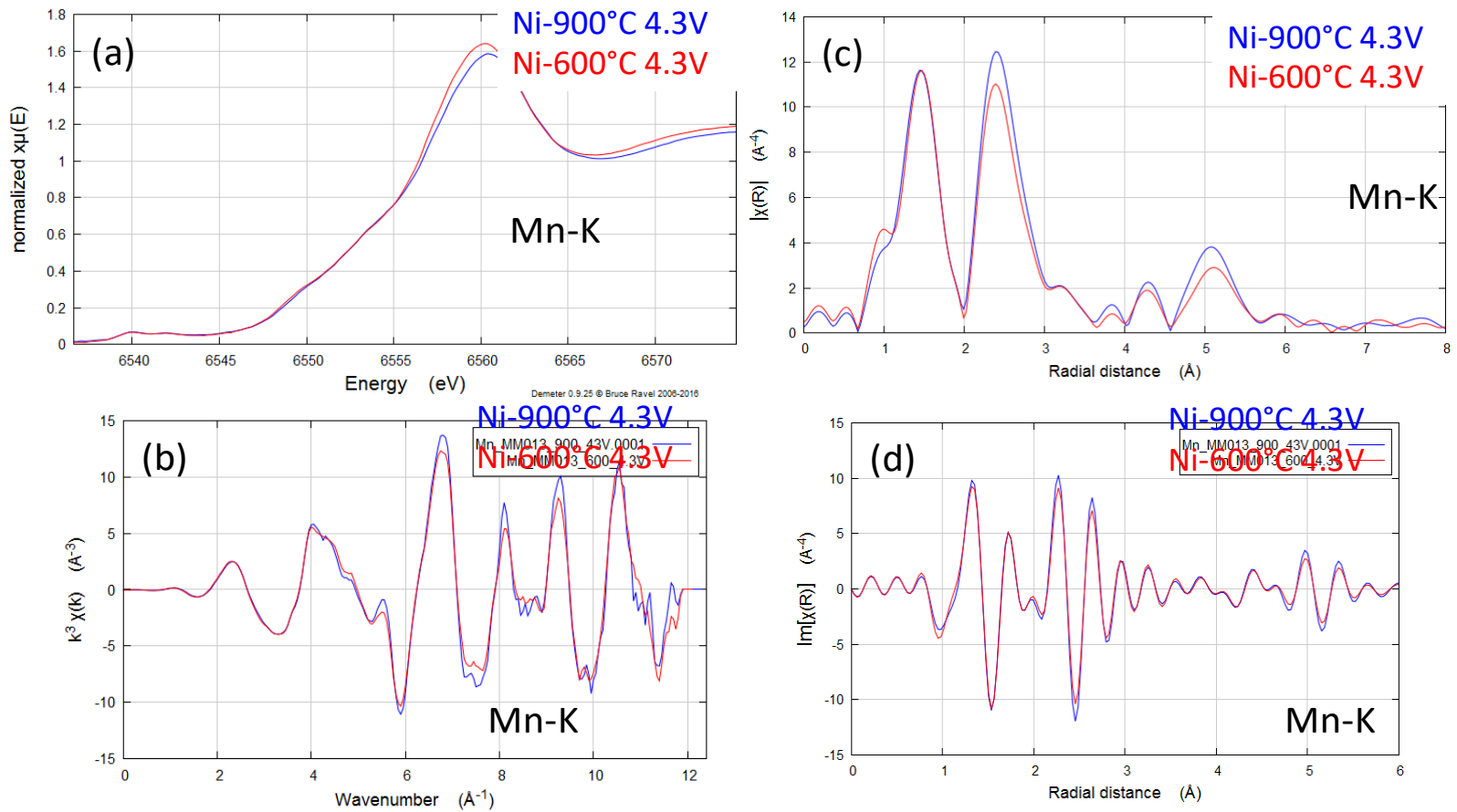

Figure S6 - (a) Mn K-edge XANES data of the Ni-600/900 ${ }^{\circ} \mathrm{C}$ samples charged to $4.3 \mathrm{~V}$. (b) Raw EXAFS, $\mathrm{k}^{3} \chi(\mathrm{k})\left(\AA^{-3}\right)$ and (c) the corresponding magnitude of the Fourier transform. (d) Imaginary part of the transform. 